T. A.

43 ... 474 ... Tomkins's standard, 1668; Father Smith's high pitch at old Durham and old St. James's Chapel Royal organs, 1683 and 1708 ; the Jordans, at St. George's, Botolph Lane, I 748 ; English A foot organs.

$45 \ldots 481 \ldots$ St. Catherine's, Hamburg, 1543.

$46 \ldots .484 \ldots$ Old smaller organ in Cathedral, Lübeck.

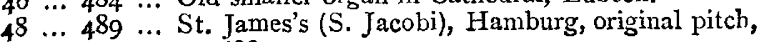
1688.

8. Church Pitch Highest.

50 ... 494 ... St. James's (S. Jacobi), Hamburg, present pitch, 1879.

$51 \ldots 496 \ldots$ Rendsburg organ, 1668.

$53 \ldots .504 \ldots$ Schlick's high pitch, I5II; Mersenne's ton de chapelle, 1636 .

$54 \ldots 506 \ldots$ Halberstadt organ, I36r.

9. Church Pitch Extreme and Chamber Fitch Highest.

$73 \ldots 563 \ldots$ Mersenne, ton de chambre, 1636.

$74 \ldots 567 \ldots$ Usual church pitch in North Germany in 1619 , called chamber pitch by Prætorius. Probable pitch of church music of Orlando Gibbons (1 583-1625).

Alexander J. Elis

\section{THE ATOMIC WEIGHT OF ANTIMONY '}

$\mathrm{IN}^{\mathrm{N}}$ a previous paper on this subject, ${ }^{2}$ we gave our reasons for the opinion, since fully confirmed, that the bromide of antimony is the most suitable compound of this element, as yet known, for determining its atomic weight; and the results of fifteen analyses of five different preparations of the bromide were published, which gave for the atomic weight in question the mean value $120^{\circ} 00$ with an extreme variation between $119^{\circ} 4$ and $120^{\circ} 4$ for all the fifteen analyses, and between $119^{\circ} 6$ and $120^{\circ} 3$ for the six determinations in which we placed most confidence. The antimonious bromide used in these determinations was purified first by fractional distillation, and secondly by crystallization from a solution in sulphide of carbon. In the crystallised product thus obtained, the bromine was determined gravimetrically as bromide of silver in the usual way. Although it seemed at the time that the results were as accordant as the analytical process would yield under the unfavourable conditions, which the presence of a large amount of tartaric acid in the solution of the bromide of antimony necessarily involved; yet it was obvious that the agreement was far from that which was desirable in the determination of an atomic weight, and our chief confidence in the accuracy of the mean value-independently of its remarkable agreement with previous results-was based on the fact that the known sources of error tended to balance each other. Hence our conclusions were stated with great caution, and the hope was expressed that after a more thorough inves. tigation of the subject we might be able "to return to the problem with such definite knowledge of the relations involved as will enable us to obtain at once more sharp and decisive results than are now possible." Unfortunately this investigation has been delayed by causes beyond our control.

In our previous paper we described a simple apparatus which we devised for subliming iodide of antimony ; and in a note to the paper we stated that we were applying the same process to the I reparation of the bromide of antimony, and that it promised excellent results. Our expectations in this respect have been fully realised, and the product leaves nothing to be desired either as regards the beauty or the constancy of the preparation. The fine acicular crystals are perfectly colourless, and have a most brilliant silky lustre. With ordinary precautions they can be kept indefinitely without change, and it is easy therefore to determine the weight of the material analysed to the tenth of a milligramme.

We have carefully studied the causes of error involyed in the analytical process of determining bromine in an aqueous solution of bromide of antimony and tartaric acid by the usual gravimetric method. These causes we propose to discuss in a future more extended paper. In this preliminary notice we have only space to state that we have satisfied ourselves that the small differences between the results previously obtained arose wholly

${ }^{x}$ Contributions from the Chemical Laboratory of Harvard College. Preliminary notice of Additional Experiments. By Josiah P. Cooke, Erving Professor of Chemistry and Mineralogy.

2 Proc. Amer. Acad. Arts and Sciences, rol. xii. page I. from the analytical process, and not from any want of constancy in the material analysed; and further that these sources of error are to a very great extent under control. Moreover, we have found that the volumetric determination of bromine by silver was not materially affected, if at all, by the same causes. We have thus been led to devise a mode of testing the atomic weight of antimony, which, while it has all the advantages of the gravimetric method previously employed, is free from its sources of error.

If the atomic weight of antimony were $122^{\circ} \mathrm{Oo}$, it would require $I .7900$ grammes of pure silver to precipitate the bromine from a solution of 2.0000 grammes of antimony bromide, while if the atomic weight of antimony were $120^{\circ} 00$ it would require $\mathbf{I} \cdot 8000$ grammes of silver. Now it is easy to estimate volumetrically $\frac{1}{10} \sigma$ of this difference with great certainty. We therefore prepared with great care a button of pure metallic silver, which we annealed and rolled out to a thin ribbon. We then weighed out from two to four grammes of bromide of antimony, prepared by sublimation as described above, and dissolved this salt in an aqueous solution of tartaric acid, which we then transferred to a litre flask and diluted to about 500 cubic centimetres. We next very accurately weighed out a quantity of silver slightly less than that which calculation showed was required for complete precipitation. This silver was dissolved in nitric acid, and the solution having been evaporated to dryness over a water bath, the silver salt was washed into the flask containing the bromide of antimony. As soon as the supernatant liquid had cleared, the small additional amount of a normal silver solution required to produce complete precipitation was run in from a burette, and measured with the usual precautions. We used no extraneous indicator, because it was important not to introduce any possibly new disturbing element into the experiment, and in the titration of bromine with silver the normal and familiar phenomena, which mark the close of the process, furnish a very sharp indication. The details of one of the determinations were as follows :-

The weight of the bromide of anatomy used amounted to 2.5032 grammes. To precipitate the bromine from the solution of this material $2 \cdot 2404$ grammes of silver would be required it $\mathrm{Sb}=122.00$ and 2.2529 if $\mathrm{Sb}=120^{\circ} 00$. We weighed out, with as much accuracy as if we were adjusting a weight, the smaller of these two quantities of metallic silver, and after dissolving the pure metal in pure nitric acid, evaporating the solution to dryness and redissolving in water, we added at once the whole of this silver solution to the litre flask containing the solution of bromide of antimony, in the manner described above. It was then found that $12 \frac{4}{10}$ cubic centimetres of a normal silver solution (one gramme of silver to the litre) were required to complete the precipitation. It will be seen that the weights of the bromile of antimony and silver used could be thus determined with the most absolute precision, and we have the greatest confidence in these values to the 1 of a milligramme. More over, it will be noticed that the volumetric method is only used to estimate the difference in the atomic weight which has been in question, and that if the method were only accurate to the $\frac{1}{10}$ of the quantity to be measured it would give us the value of the atomic weight within $\frac{2}{10}$ of 2 unit; while if, as we had reason to believe, the process was accurate within I per cent, it would fix the atomic weight within $\frac{2}{\mathrm{I} \sigma \mathrm{E}}$ of a unit.

By the method just described, the following results we: obtained. The letters $a$ and $b$ indicate different preparations.

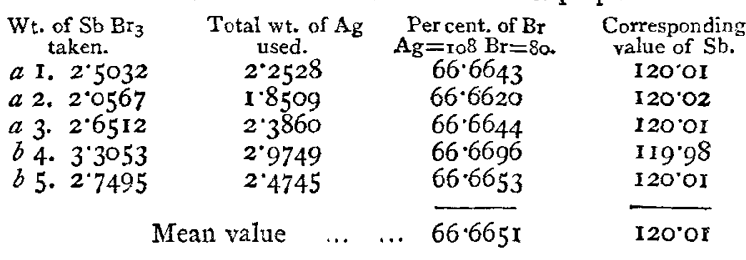

Mean value of fifteen gravimetric de- $\} 66 \cdot 6665$

$\begin{array}{llll}\text { Theory Sb. I } 20 \text { requires } \quad \ldots & \ldots & 66.6666\end{array}$
," Sb. 122
,,
... $\quad \ldots \quad 66 \cdot 2983$

In order still further to control the work, we collected the bromide of silver formed in the last two determinations, washing the precipitate with the precautions which experience had shown to be nece:sary, and determining its weight, first, after drying at $150^{\circ} \mathrm{C}$. and, secondly, after heating to incipient fusion. In 
$b 6$ there was a loss of $\frac{1}{10}$ of a milligramme; in $b 7$ a loss of $\frac{2}{10}$ of a milligramme only at the second weighing. This is an absolute proof that there could be no sensible occlusion of any tartaric acid or any tartrate by these precipitates, and, as stated in our original paper, the same test was frequently applied, although not always in our previous determinations. It is also evident that these last experiments give us two essentially distinct determinations of the atomic weight, although the materials employed were identical with those of $b 4$ and $b 5$.

\begin{tabular}{|c|c|c|c|}
\hline $\begin{array}{l}\text { Wt. of } \mathrm{Sb} \mathrm{Br} \\
\text { taken. } \\
\text { b } 6.3^{*} 3{ }^{\circ} 53 \\
\text { b } 7 \cdot 2^{\cdot} 7495\end{array}$ & $\begin{array}{c}\text { Wt. of AgBr } \\
\text { determined. } \\
5 \cdot 1782 \\
4 \cdot 3076\end{array}$ & $\begin{array}{c}\text { Per cent. of bromine } \\
\text { Ag }=108 \mathrm{Br}=80 . \\
66.665 \\
66.667\end{array}$ & $\begin{array}{l}\text { Corresponding } \\
\text { value of } \mathrm{Sb} \text {. } \\
\text { I } 20^{\circ} \mathrm{OI} \\
120^{\circ} 00\end{array}$ \\
\hline & lue & 66.666 & $120^{\circ} 00$ \\
\hline
\end{tabular}

Lastly, it is obvious that these gravimetric determinations, taken in connection with the corresponding volumetric results, give us the most conclusive evidence of the purity, both of the metallic silver used, and also of the bromine in the bromide of antimony, which is the basis of this atomic weight investigation. By comparing $b 6$ and $b 7$ with $b 4$ and $b 5$ respectively, we obtain the following data:-

r. $2^{*} 9749$ gram. of silver gave $5^{\circ} 1782$ gram. bromide of silver. 2. $2 \cdot 4745$

Hence it follows that, as shown by these experiments, the proportions of the silver to the bromine were respectively :-

\section{I08:00 Silver to $79^{\circ} 99$ Bromine. \\ 2. $108.00 " 80 \circ 01 "$ \\ Mean value $\overline{108.00}, \overline{80.00}$,}

This is the ratio of the atomic weight of silver to that of bromine, and corresponds to the second decimal place with the determinations of Stas as well as with those of Dumas.

In conclusion it gives as pleasure to express our obligations to Mr. G. De N. Hough and Mr. G. M. Hyams, two students of this laboratory, who have greatly aided us in the experimental work of this investigation.

\section{SOCIETIES AND ACADEMIES LONDON}

Royal Society, March 11.- "Report on the Fossil Flora of Alum Bay," by Baron Ettingshausen. The materials upon which the report is based were stated to be in the British Museum, Museum of Practical Geology, Woodwardian Museum, and in Mr. J.S. Gardner's collections. The fossil flora of Alum Bay contains, according to the author, about 116 genera and 274 species belonging to 63 families. Of these genera 3 are said to be Thallophyta, 2 Filices, 5 Gymnospermæ, 6 Monocotyledons, 28 A petalæ, 15 Gamopetalæ, 54 Dialypetalæ, and 2 indeterminable. A number of genera are enumerated which the author supposes to be common to Alum Bay and Sheppey, and hence he infers, as Heer did, that there is a close connection between the two floras. The small number of ferns and palms in comparison with the much greater number at Bournemouth and of palms at Sheppy is remarkable. Many of the dicotyledons are stated to show a genetic connection with miocene species, and a great number of the latter are seen to have originated as far back as the eocene. On the other hand some of the miocene genera were not completely differentiated into renera in the eocene period. Two examples are given : Castanea, which although perfectly developed in the miocene, is said to be only represented in the eocene by a castanea-like oak, uniting characters now distinctive of the two genera, and a Pomaderris-like Rhamnus, also seeming to unite two genera which were quite distinct from each other in the miocene.

More than fifty of the species from Alum Bay are common to Sotzka and Hæring, while a lesver number are common to Sézanne, the Lignitic of America, and to other floras. The paper includes a list of species.

In the discussion Dr. Carruthers could not quite agree with determinations which brought together plants from all parts of the globe. Mr. Mitchell questioned the utility of giving specific names to plant remains that are neither described nor figured, especially when no nearer approx mation to their position can be made than is indicated by the terms Carpolithes and Phyllites. Mr. Gardner explained the position of the leaf-bed at Alum Bay, stating it to be a small vertical clay basin, similar to those found in a horizontal position near Bournemouth; and hence be did not consider it remarkable that the flora from Alum Bay should appear restricted (as indicated by the paucity of palms and ferns) by comparison with the Bournemouth flora, which hos been obtained from a series of basins extending for several miles.

Chemical Society, March 3o.-Anniversary meeting.-Mr. Warren De la Rue, president, in the chair. The president, in his annual address, contrasted the condition of the Society during the past year with its position in 1869 . The number of Fellows has increased from 522 to 1,034 , the income from $\mathrm{I}, 100 l$. to $2,700 l$.; papers read from 31 to 75 . A rapid glance was then taken of the recent progress of chemistry, especial reference being made to the decomposition of the elements chlorine, bromine, \&c., by Meyer; the photographs of the whole of the spectrum recently made by Capt. Abney; the artificial production of the diamond by Hannay; the synthesis of yegetable colouring matters and alkaloids; the discovery of a new element, scandium, \&c. The officers for the ensuing year were then balloted for; the following were elected:-President-H. E. Roscoe. Vice.presidents-F. A. Abel, C.B., B. C. Brodie, Warren De la Rue, E. Frankland, J. H. Gladstone, A. W. Hofmann, W. Odling, Lyon Playfair, A. W. Williamson, J. Dewar, J. H. Gilbert, N. S. Maskelyne, V. Harcourt, R. Angus Smith, J. Young. Secretaries-W. H. Perkin, H. E. Armastrong. Foreign Secretary-Hugo Muiller. Treasurer-W. J. Russell. Other members of council-M. Carteighe, C. Graham, C. W. Heaton, H. McLeod, E. J. Mills, J. M. Thomson, W. C. Roberts, W. A. Tilden, W. Thorp, T. E. Thorpe, J. L. Thudichum, R. Warington.

Anthropological Institute, March 23.-Edward B. Tylor, F.R.S., president, in the chair. - A paper by Mr. V. Ball, M.A., F.G.S., on Nicobarese ideographs was read. As the Andamanese may be said to have not progressed in civilisation beyond that stage which was represented by the people of the early stone periods in Europe, so the Nicobarese, who are much less savage and degraded than their neighbours of the Andamans, may justly be compared with the inhabitants of the "bronze period." The example of Nicobarese picture-writing described by the author was obtained in the year 1873 on the island of Kondul, where it was hanging in the house of a man who was said to have died a short time previously; it is now in the Museum of Science and Art at Dublin. The material of which it is made is either the glume of a bamboo or the spathe of a palm which has been flattened out and framed with split bam. boos. It is about three feet long by eighteen inches broad. The objects are painted with vermilion, their outlines being surrounded with punctures which allow the light to pass through. Suspended from the frame are some cocoanuts and fragments of hog's flesh. The figures of the sun, moon, and stars occupy prominent positions. Attention was directed to M. Maclay's description of a Papuan ideograph which symbolised the various guests present at a feast given in celebration of the launch of two large canoes (vide NATURE, vol. xxi. p. 227).-Mr. Alfred Tylor read a paper on a new method of expressing the law of specific changes and typical differences of species and genera in the organic world, and especially the cause of the particular form of man. The lower animals have no abstract ideas, and therefore all they can know must be derived from objects. Their reproduction of specific form and decoration seems to prove that they possess a mental power of appreciating the niceties of form and colour in a very high degree The forms and decorations of organised beings seem to be regulated by laws which the author provisionally called emphasis and symmetry. Emphasis was defined as the marking out by form or decoration of the important parts or organs. The law of emphasis, as applied to human work, was illustrated by the structure of a Greek temple, in which all the parts have their functions expressed or emphasised by ornament. It is a remarkable fact, and one that can scarcely be accidental, that just as animals fall naturally into two great classes, the vertebrata and invertebrata, so the emphasised functional decorations group themselves into two classes, and these two classes are identical with the vertebrata and the invertebrata. In the vertebrata the emphasised ornamentation is what we may call axial, being the outward expression of the central axis or vertebral column with its appendages; and in the invertebrata the decoration tends to follow the outline of the animal, and so develops borders. It has always excited wonder that the child-a separate individual-should inherit and 